\title{
Formation of Zoonoses in the South of Russia: Climate Change and Anthropogenic Factors Expanding the Area of Zoonosis
}

\author{
Pushkin Sergey Viktorovich ${ }^{1 *(1)}$ \\ ${ }^{1}$ Faculty of Medicine and Biology, North Caucasus Federal University, Stavropol, Russia
}

$\mathrm{W}$ e mainly analyzed the situation for a number of climate-dependent transmissible diseases of various etiologies in territories of southern Russia and also assessed the possible impact of climate change on the vectors of pathogens by mathematical modeling using climate predictors.

Hemorrhagic fever with renal syndrome is a nontransmissible viral zoonosis widespread in Russia. It is considered one of the most important natural focal diseases. We examined leptospirosis and tularemia as climate-dependent diseases of bacterial etiology. Leptospirosis is transmitted only non-transmissively, while tularemia, in addition to a number of nontransmissible pathways, is characterized by a facultativetransmissible pathway, and arthropods, primarily bloodsucking dipterans, act as mechanical carriers.

Among the transmissible natural focal diseases of various etiologies, we examined tick-borne encephalitis, ixodid tick-borne borreliosis (Lyme disease), tickborne typhus (tick-borne rickettsiosis), and Crimean hemorrhagic fever.

The first three diseases are predominant in Russia. Overall, the incidence of tick-borne encephalitis in Russia has been decreasing in the last decade, while the incidence of Lyme disease is growing. Crimean hemorrhagic fever is recorded sporadically in the South and North Caucasian Federal Districts (1).

West Nile fever is one of the most important natural focal diseases transmitted by mosquitoes. The most unfavorable situation was observed in Astrakhan, Volgograd, and Rostov regions. They account for the vast majority of cases of the disease.

A classic example of anthroponosis is malaria. The epidemiological situation at the present time can be considered favorable given that the number of imported cases is small (about a hundred per year) and local cases are rare. However, malaria is also a classic example of a disease that can quickly regain its position when control is loosened.

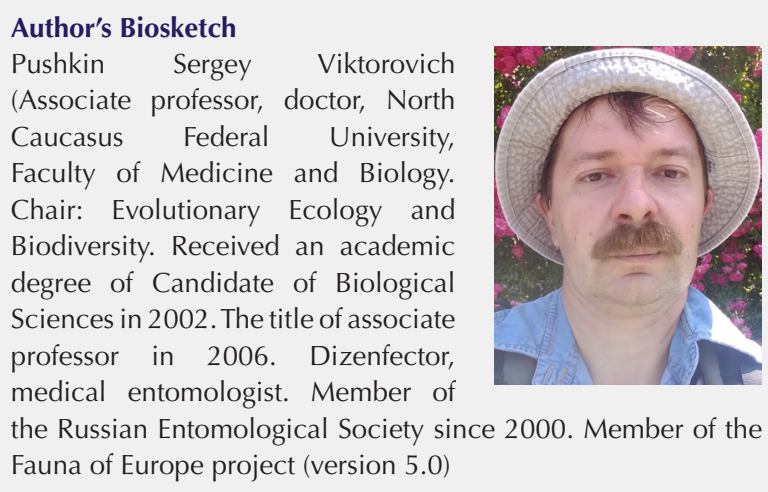

Model analysis of changes in the distribution of Ixodidae mites and malaria mosquitoes showed that their habitats were influenced by the observed climate change which is significantly expanding in the northern and eastern regions, and the reduction is negligible.

The prerequisites for an increase in the incidence of these infections and their wider spread persist.

Climate-related risk factors include expansion of the areas of arthropod vectors and an increase in their numbers, as well as a similar increase in the number and expansion of the areas of vertebrates, mainly murine rodents, which are reservoirs of natural focal infections and carriers of vectors in nature. A new risk factor is the importation of exotic vectors into the territory of Russia, as well as their rooting, the importance of which increases with the expected warming.

Countermeasures (adaptation measures) against climate-dependent infections include prevention (vaccination), strengthening monitoring of the species composition and number of vectors and reservoirs of infections, and increasing the scale and effectiveness of combating them (2). These measures also include personal protective equipment against them. The enhancement of the effectiveness of these measures should be based not only on the actual improvement of these funds but also on the improvement of the sanitary and epidemiological 
surveillance of the population.

\section{Conflict of Interests}

None.

Ethical Issues

Not applicable.

\section{References}

1. Pushkin SV. Zoodiversity. [Russian]. Moscow, Berlin: DirectMedia, 2019. doi:10.23681/575401

2. Victorovich PS, Pavlovich IM. Endemism, relicts and invasion spices of animals in structure of the biodiversity of the Ciscaucasia. Entomol Appl Sci Let. 2018;4(3):17-20.

(C) 2021 The Author(s); This is an open-access article distributed under the terms of the Creative Commons Attribution License (http:// creativecommons.org/licenses/by/4.0), which permits unrestricted use, distribution, and reproduction in any medium, provided the original work is properly cited. 